\title{
Restoration-type Outcome of Freehand Implant Placement in Single Edentulous Gaps: An Observational Study
}

\author{
Linah M Ashy
}

\begin{abstract}
Aim: To determine the restoration-type outcome of implants placed freehanded in single edentulous gaps.

Materials and methods: Forty-nine implant analogs present in working models of 46 patients representing implants placed freehand with no surgical guides in single edentulous gaps were included in this study. Each model was scanned using an optical scanner and a cone beam-CT. Simplant Pro18 software was used to create a virtual tooth replacing the missing tooth in the scanned model. Two virtual implants were created; one superimposed on the implant analog of the model and a second in relation to the virtual crown with its long axis passing through the cingulum or perpendicular to the occlusal table of the virtual crown. Measurement of angular deviation in the position of the placed implant from that of the planned implant was calculated.

Results: The average deviation in the position of placed implants was $9.78 \pm 6.47$ degrees angular deviation. There was no statistically significant difference in the extent of angular deviation between maxillary and mandibular implants. Whereas, there was a statistically significant difference between anterior and posterior implants. Clinically, $70.57 \%$ of the placed anterior implants, $29.41 \%$ of premolar implants, and $20 \%$ of molar implants need to be restored with cement-retained crowns.

Conclusion: For single edentulous gaps, the potential for a cement-retained implant crown is significantly higher with freehand implant placement in the anterior than in the posterior regions.

Clinical significance: With freehand implant placement in anterior single edentulous gaps, the potential for a cement-retained implant crown outcome is significantly higher than in posterior gaps. Maximum precision in implant treatment planning and placement is required in this region of the mouth to achieve optimum results.

Keywords: Freehand implant placement, Restoration outcome, Retrospective observational study.

The Journal of Contemporary Dental Practice (2019): 10.5005/jp-journals-10024-2706
\end{abstract}

\section{INTRODUCTION}

Dental implants in single edentulous gaps are often restored with either a screw-retained or a cement-retained implant crowns. Both treatment options were widely investigated in the literature for their indications, survival rate, biologic, and mechanical complications. ${ }^{1-5}$ Reviews comparing the two restorative modalities have concluded a comparable rate of survival and complications, similar bone and soft-tissue response, and satisfactory esthetic results with the use of zirconia abutments. ${ }^{6-11}$ However, the screwretained restoration is gaining popularity lately for some reasons; first, the residual cement of cement-retained restorations was shown to be associated with significant peri-implant tissue loss ${ }^{12,13}$ and second, the predictable retrievability of the screw-retained restoration suggests an obvious advantage of the later restorative option. Therefore, the primary indication for cement-retained restorations was proposed for correcting angled implants. ${ }^{14}$ The decision on the restoration type for dental implants is influenced by the implant position outcome. Implant positioning in a single edentulous gap can often be considered as both an uncomplicated and a complicated practice. The procedure might seem to be undemanding due to the presence of landmarks from adjacent and opposing dentition. However, a great deal of care must be paid to the appropriate positioning if a successful overall treatment outcome is desired. ${ }^{15,16}$ Clinicians can choose to place implants in single edentulous gaps with or without the aid of surgical stents. The aim of this study is to determine the restoration-type outcome of implants placed freehanded in single edentulous gaps. The specific objectives are:
Department of Oral and Maxillofacial Prosthodontics, Faculty of Dentistry, King Abdulaziz University, Jeddah, Kingdom of Saudi Arabia Corresponding Author: Linah M Ashy, Department of Oral and Maxillofacial Prosthodontics, Faculty of Dentistry, King Abdulaziz University, Jeddah, Kingdom of Saudi Arabia, Phone: +966 126403443, e-mail: lashy@kau.edu.sa

How to cite this article: Ashy LM. Restoration-type Outcome of Freehand Implant Placement in Single Edentulous Gaps: An Observational Study. J Contemp Dent Pract 2019;20(11):1274-1278.

Source of support: Nil

Conflict of interest: None

- To determine the extent of deviation of freehand implants placed in single edentulous gaps from a screw-retained restoration position.

- To compare the deviation outcome between different areas.

\section{Materials and Methods}

This work was approved by the Research Ethics Committee of the Faculty of Dentistry at King Abdulaziz University, Jeddah, Kingdom of Saudi Arabia (proposal number 014-01-18).

\section{Study Samples}

The study included 49 dental implant analogs of a bone level type (19 PrimaConnex, 12 Straumann, 11 Astra, 4 Nobel Biocare, and 3 Zimmer dental implant systems) present in working models 
of 46 patients. These analogs represent implants placed in single edentulous gaps through an open flap procedure during the period between February 2016 and December of 2017. The implants were placed in the anterior or posterior regions of either the maxilla or mandible by surgeons of different levels of experience without the use of a surgical guide. Table 1 shows the number and distribution of implant analogs.

\section{Models Scanning}

Each model was radiographically scanned using cone beam CT (i-CAT) and optically scanned using a 3D lab scanner (Maestro 3D Dental scanner).

\section{Images Alignment}

Resultant images of each model, the DICOM and the STL datasets, were imported into Simplant dental implant treatment planning software SimPlant PRO 18 (Materialize NV), where they were aligned precisely.

\section{Virtual Planning}

Using Simplant software program, a virtual tooth was created to replace the missing tooth at the single edentulous gap on the 3D STL image of the model. A virtual implant, $3.75 \mathrm{~mm}$ in diameter and $10 \mathrm{~mm}$ in length, was then placed in relation to the virtual crown in a position compatible with a screw-retained implant crown. The long axis of the virtual implant passes through the cingulum of an anterior virtual crown or perpendicularly through the occlusal table of a posterior virtual crown. This virtual implant was labeled as the "planned implant." A second virtual implant was also created and superimposed on the actual analog in the 3D DICOM image of the same model and labeled as the "placed implant" (Fig. 1).

\section{Measurement of Deviations}

All measurements were performed by the author, who was blinded to the patients and surgeons involved in this study. The amount of angular deviation of the placed implant from the planned implant was calculated in degrees using the Simplant software. Angular deviation was defined as the angle between the longitudinal axes of the planned and placed implants (Fig. 2). Also, the exit point of the prosthetic space of the placed implant through the virtual crown was reported.

\section{Statistical Analysis}

Descriptive statistics were used for frequencies, percentages, means, and standard deviations (SDs). Statistical analysis was conducted using IBM SPSS version 22. One-way ANOVA and student $t$ test were used to examine the association between variables at the significance level of $5 \%(p<0.05)$.

\section{Results}

Angular deviations in the position of all included 49 placed implants from corresponding planned implants were measured.

Table 1: Number of dental implant analogs according to their location in the dental arch

\begin{tabular}{ll}
\hline Implant analog location & Implant analog number $(n=49)$ \\
\hline Maxilla & 33 \\
Mandible & 16 \\
Anterior & 17 \\
Premolar & 17 \\
Molar & 15 \\
\hline
\end{tabular}

Comparisons of deviations were performed for anterior implants vs premolar implants vs molar implants and for maxillary implants vs mandibular implants. Tables 2 and 3 summarize means, SDs, and $p$ values for all measurements. The average angular deviation in the position of placed implants from the position of planned implants was $9.78 \pm 6.47$ degrees.

According to the region in the dental arch, there was a statistically significant difference in an angular deviation between anterior and premolar implants at $p=0.03$ and between anterior and molar implants at $p=0.05$ (Table 2 and Fig. 3). According to the type of dental arch, there was no statistically significant difference in the deviation between maxillary and mandibular implants (Table 3 and Fig. 4).

Clinically, the exit point of the prosthetic space was diverged from the cingulum of the crown in $76.47 \%$ of the anterior implants and diverged from the occlusal table in $29.41 \%$ of the premolar implants and $20 \%$ of the molar implants (Fig. 5).

\section{Discussion}

This retrospective observational study shows that the conventional freehand implant placement for the treatment of a single anterior missing tooth is associated with a high potential for a cementretained implant restoration outcome as a result of an angled implant position. In this study, the restoration type options were significantly more limited in the anterior than in the posterior regions of the mouth. Due to the location of the exit point of prosthetic space representing the location of prosthetic screw access hole, $70.57 \%$ of the placed anterior implants, $29.41 \%$ of premolar implants, and $20 \%$ of molar implants need to be restored with cement-retained crowns. Consistent with this finding, a recent study reported that $19.2 \%$ of implants that were freehand placed at molar sites had to be restored with a cement-retained restoration. ${ }^{17}$ However, Van de Velde et al., considered the placement of implants at molar sites the simplest from the angulation standpoint. ${ }^{18}$ Findings of the present study agree with that opinion since molar crowns have the largest occlusal table circumference that can compensate for angular deviations of implants better than anterior and premolar crowns.

The deviation from an implant position that would allow for a screw-retained implant crown could be due to several factors. These may include bone-driven implant placement due to the insufficiency of bone quantity. The alveolar crest of the anterior edentulous area of the mouth commonly has reduced dimensions and/or facial bone undercut. ${ }^{15}$ Such ridge morphology dictates the placement of implants in an angle and frequently necessitates alveolar ridge augmentation. In addition, not using a surgical guide increases the risk of inaccuracies. Previous studies reported that freehand implant placement is associated with significant positional deviations. ${ }^{17-20}$ In a randomized controlled clinical trial evaluating the accuracy of freehand, pilot-drill, and fully guided placement of multiple implants in the posterior maxilla, the deviation of implant position from the ideal position in the freehand group was reported to be $6.99 \pm 0.87$ degree angular deviation, $0.53 \pm 0.09$ $\mathrm{mm}$ depth deviation, $1.27 \pm 0.11 \mathrm{~mm}$ lateral coronal deviation and $1.97 \pm 0.19 \mathrm{~mm}$ lateral apical deviation. ${ }^{17}$ Consistently, Vermeulen in a comparative in vitro study has reported 7.12 degrees angular deviation, $0.59 \mathrm{~mm}$ depth deviation, $1.13 \mathrm{~mm}$ lateral coronal deviation, and $1.11 \mathrm{~mm}$ lateral apical deviation of implants placed by experienced surgeons with the freehand approach in single edentulous spaces in the anterior maxilla. ${ }^{19}$ Other factors that can 

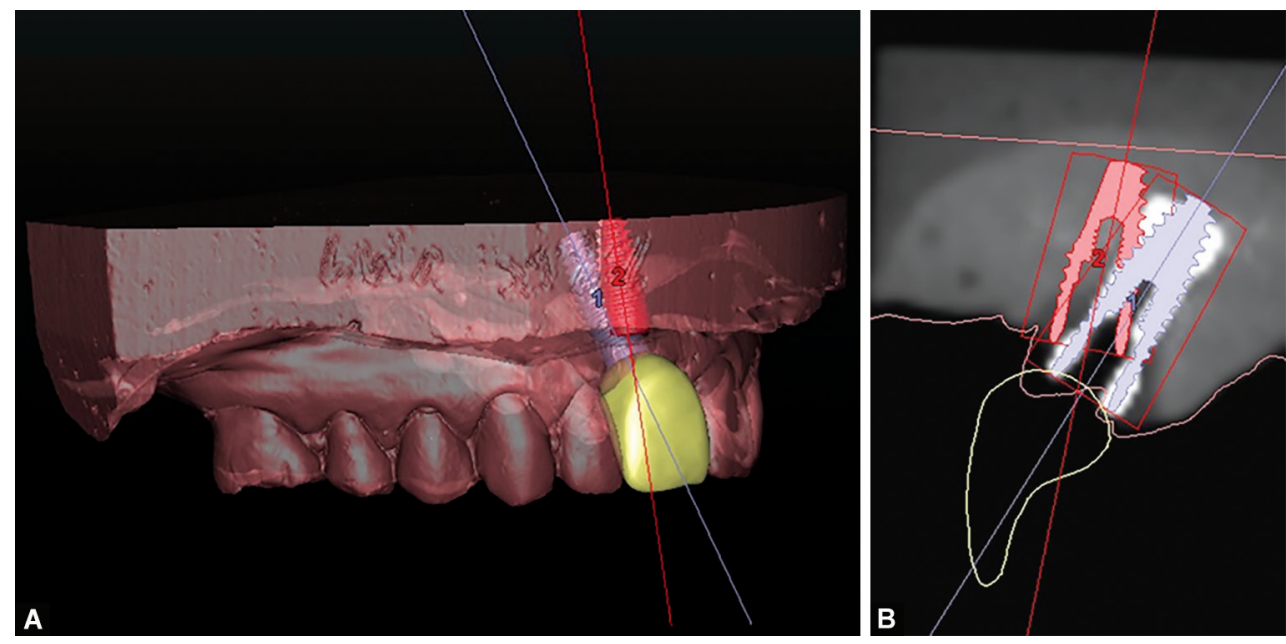

Figs $1 \mathrm{~A}$ and B: Optical scan and CBCT images of a working model. Virtual "placed" implant (in blue) is superimposed on the analog and a second virtual "planned" implant (in red) is placed in an angle compatible with a screw-retained implant crown

Table 2: Deviation of placed implant position from planned implant position according to implant site in the dental arch

\begin{tabular}{ll}
\hline & Angular deviation $\left({ }^{\circ}\right)$, mean $(S D)$ \\
\hline Anterior implants & $13.24(8.39)^{*}$ \\
Premolar implants & $7.86(3.89)^{*}$ \\
Molar implants & $8.04(4.86)^{*}$ \\
All implants & $9.78(6.47)$ \\
$p$ value & 0.021 \\
\hline
\end{tabular}

*Statistically significant difference at $p<0.05$

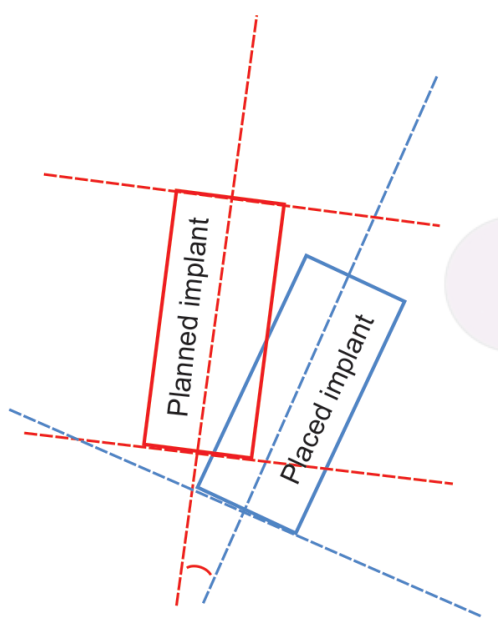

Fig. 2: Illustration of measurement of angular deviation in position between placed and planned implants

contribute to deviation in implant position are the low level of experience of a surgeon or lack of communication between the restoring dentist and the surgeon.

In this study, the reported angular deviation was $9.78 \pm 6.47$ degrees, which are higher than those reported in previous studies in the literature. ${ }^{17,19}$ Variation in the extent of deviation reported in the current investigation from those reported in other studies could be due to several implications. First, the virtual planned
Table 3: Deviation of placed implant position from planned implant position according to dental arch type

\begin{tabular}{ll}
\hline & Angular deviation $\left({ }^{\circ}\right)$, mean $(S D)$ \\
\hline Maxillary implants & $10.52(7.15)$ \\
Mandibular implants & $8.11(4.33)$ \\
$p$ value & 0.234 \\
\hline
\end{tabular}

No statistically significant difference at $p<0.05$

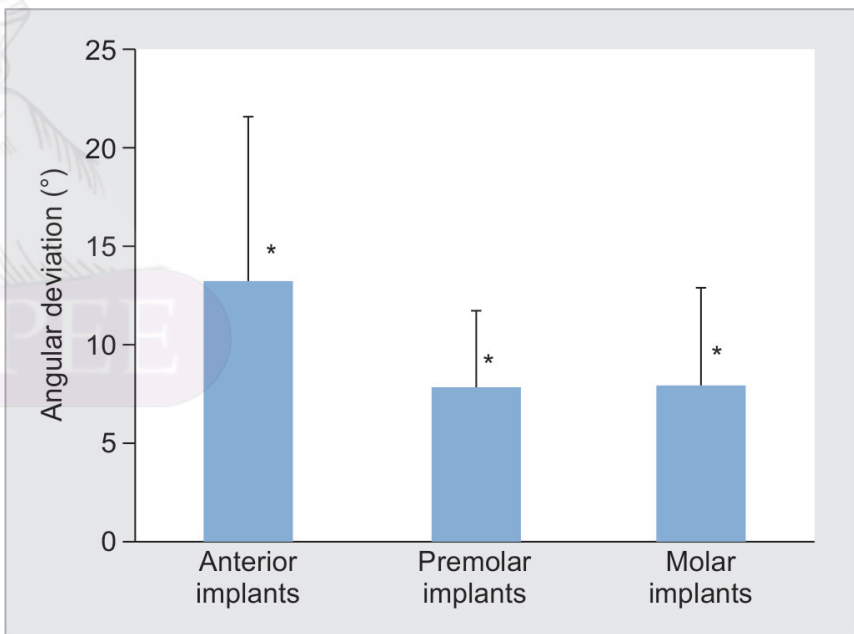

Fig. 3: Means and standard deviations, in degrees, of angular deviation of placed implants from planned implants at in different regions in the dental arch. * ${ }^{*}$ tatistically significant difference at $p<0.05$

implant here was placed, subsequent to the actual placed implant, in the ideal position for a screw-retained implant crown without consideration of the underlying bone situation. Whereas in preceding studies, the virtual planned implant was placed prior to the actual implant placement taking into consideration the condition of the underlying bone. Other implications for variations may include the level of experience of clinicians, ${ }^{21,22}$ the type of the study being in vivo or in vitro, ${ }^{23}$ the edentulous gap being single 


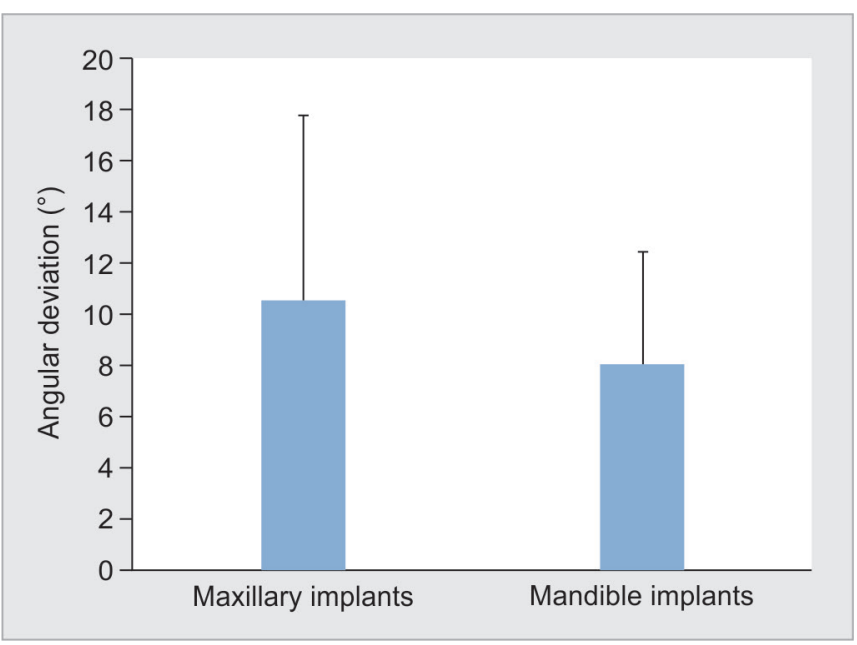

Fig. 4: Means and standard deviations, in degrees, of angular deviation of placed implants from planned implants in the maxillary arch vs the mandibular arch. No statistically significant difference at $p<0.05$

or extended, the surgical protocol regarding flap reflection, and the site of implant placement being in the anterior or posterior regions of the dental arch.

Shortcomings of the current investigation include, not reporting the condition of underlying bone, nor the level of experience of involved surgeons, therefore the exact cause of the observed deviation in implant position cannot be concluded.

In summary, when placing implants in anatomically and esthetically challenging anterior areas, the demand for accurate outcome increases. Therefore, thorough examination, diagnosis, treatment planning, and accurate implant placement are paramount for a successful overall treatment. More controlled clinical trials are needed on the placement of implants without a surgical guide in single edentulous gaps to delineate the standard of care protocol based on various site-specific, patient, and clinician related factors.

\section{Conclusion}

For single edentulous gaps, the potential for a cement-retained implant crown is significantly higher with freehand implant placement in the anterior than in the posterior regions.

\section{Clinical Significance}

With freehand implant placement in anterior single edentulous gaps, the potential for a cement-retained implant crown outcome is significantly higher than in posterior gaps. Maximum precision in implant treatment planning and placement is required in this region of the mouth to achieve optimum results.

\section{Acknowledgments}

The author would like to thank faculty members and residents at KAUFD, Jeddah, Kingdom of Saudi Arabia, who generously provided dental models included in this study. Special thanks should also be given to Mr Majed Qahtani of the radiology department, KAU Hospital and to Mr Hassan Mahboob from the research laboratory, KAUFD, for their help with scanning models.

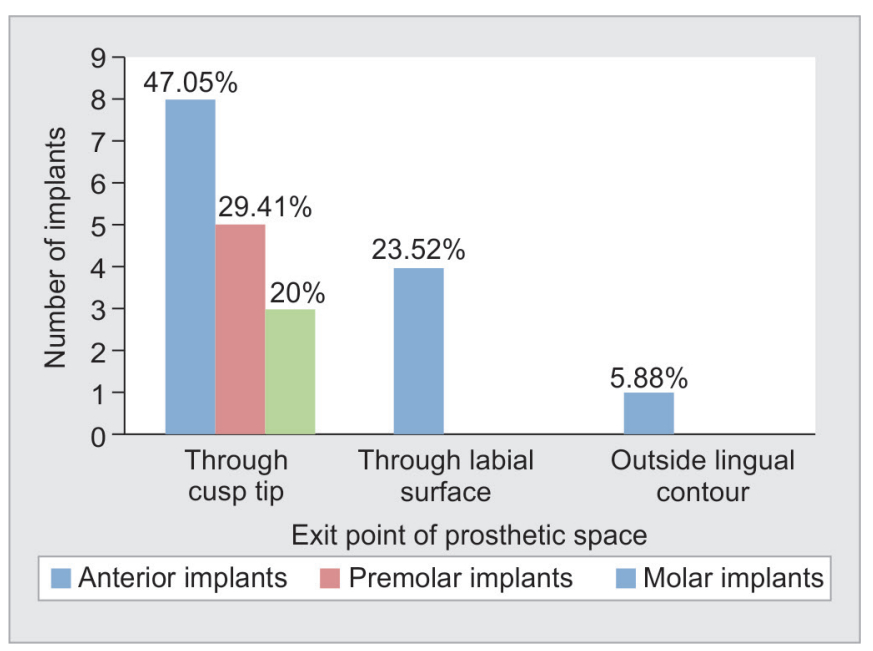

Fig. 5: Number and percentages of placed implants indicating exit point of prosthetic space

\section{References}

1. Henry PJ, Laney WR, Jemt T, et al. Osseointegrated implants for single-tooth replacement: a prospective 5-year multicenter study. Int J Oral Maxillofac Implant 1996;11(4):450-455.

2. Chee W, Felton DA, Johnson PF, et al. Cemented vs screw-retained implant prostheses: which is better? Int J Oral Maxillofac Implant 1999;14(1):137-141.

3. Chee W, Jivraj S. Screw vs cemented implant supported restorations. Br Dent J 2006;201(8):501-507. DOI: 10.1038/sj.bdj.4814157.

4. Vigolo P, Mutinelli S, Givani A, et al. Cemented vs screw-retained implant-supported single-tooth crowns: a 10-year randomized controlled trial. Eur J Oral Implantol 2012;54(4):355-364.

5. Amorfini L, Storelli S, Mosca D, et al. Comparison of cemented vs screw-retained, customized computer-aided design/computerassisted manufacture zirconia abutments for esthetically located single tooth implant: a 10-year randomized prospective study. Int J Prosthodont 2018;31(4):359-366. DOI: 10.11607/ijp.5305.

6. Michalakis KX, Hirayama H, Garefis PD. Cement-retained vs screwretained implant restorations: a critical review. Int J Oral Maxillofac Implant 2003;18(5):719-728.

7. Weber HP, Kim DM, Ng MW, et al. Peri-implant soft tissue health surrounding cement- and screw-retained implant restorations: a multicenter, 3-year prospective study. Clin Oral Implant Res 2006;17(4):375-379. DOI: 10.1111/j.1600-0501.2005.01232.x.

8. Sailer I, Mühlemann S, Zwahlen M, et al. Cemented and screw-retained implant reconstructions: a systematic review of the survival and complication rates. Clin Oral Implant Res 2012;23(Suppl 6):163-201. DOI: 10.1111/j.1600-0501.2012.02538.x.

9. Lemos CA, de Souza Batista VE, Almeida DA, et al. Evaluation of cementretained vs screw-retained implant-supported restorations for marginal bone loss: a systematic review and meta-analysis. J Prosthet Dent 2016;115(4):419-427. DOI: 10.1016/j.prosdent.2015.08.026.

10. Wittneben JG, Millen C, Brägger U. Clinical performance of screwvs cement-retained fixed implant-supported reconstructions-a systematic review. Int J Oral Maxillofac Implant 2014;29(Suppl):84-98. DOI: 10.11607/jomi.2014suppl.g2.1.

11. Millen C, Brägger U, Wittneben JG. Influence of prosthesis type and retention mechanism on complications with fixed implant supported prostheses: a systematic review applying multivariate analyses. Int J Oral Maxillofac Implant 2015;30(1):110-124. DOI: 10.11607/jomi.3607.

12. Pauletto N, Lahiffe BJ, Walton JN. Complications associated with excess cement around crowns on osseointegrated implants: a clinical report. Int J Oral Maxillofac Implant 1999;14(6):865-868. 
13. Kotsakis GA, Zhang L, Gaillard P, et al. Investigation of the association between cement retention and prevalent peri-implant diseases: a cross-sectional study. J Periodontol 2016;87(3):212-220. DOI: 10.1902/ jop.2015.150450.

14. Priest G. A current perspective on Screw-retained single-implant restorations: a review of pertinent literature. J Esthet Restor Dent 2017;29(3):161-171. DOI: 10.1111/jerd.12283.

15. Buser D, Martin W, Belser UC. Optimizing esthetics for implant restorations in the anterior maxilla: anatomic and surgical considerations. Int J Oral Maxillofac Implant 2004;19(Suppl):43-61.

16. Morton D, Chen ST, Martin WC, et al. Consensus statements and recommended clinical procedures regarding optimizing esthetic outcomes in implant dentistry. Int J Oral Maxillofac Implant 2014;29(Suppl):216-220. DOI: 10.11607/jomi.2013.g3.

17. Younes F, Cosyn J, De Bruyckere T, et al. A randomized controlled study on the accuracy of free-handed, pilot-drill guided and fully guided implant surgery in partially edentulous patients. J Clin Periodontol 2018;45(6):721-732. DOI: 10.1111/jcpe.12897.

18. Van de Velde T, Glor F, De Bruyn H. A model study on flapless implant placement by clinicians with a different experience level in implant surgery. Clin Oral Implant Res 2008;19(1):66-72.
19. Vermeulen J. The accuracy of implant placement by experienced surgeons: guided vs freehand approach in a simulated plastic model. Int J Oral Maxillofac Implant 2017;32(3):617-624. DOI: 10.11607/ jomi.5065.

20. Nickenig HJ, Wichmann $\mathrm{M}$, Hamel J, et al. Evaluation of the difference in accuracy between implant placement by virtual planning data and surgical guide templates vs the conventional free-hand method-a combined in vivo-in vitro technique using cone-beam CT (Part II). J Craniomaxillofac Surg 2010;38(7):488-493. DOI: 10.1016/ j.jcms.2009.10.023.

21. Payer $M$, Kirmeier R, Jakse N, et al. Surgical factors influencing mesiodistal implant angulation. Clin Oral Implant Res 2008;19(3): 265-270. DOI: 10.1111/j.1600-0501.2007.01464.x.

22. Walton JN, Huizinga SC, Peck CC. Implant angulation: a measurement technique, implant overdenture maintenance, and the influence of surgical experience. Int J Prosthodont 2001;14(6):523-530.

23. Bover-Ramos F, Viña-Almunia J, Cervera-Ballester J, et al. Accuracy of implant placement with computer-guided surgery: a systematic review and meta-analysis comparing cadaver, clinical, and in vitro studies. Int J Oral Maxillofac Implant 2018;33(1):101-115. DOI: 10.11607/ jomi.5556. 